\section{Duplicando a Antropologia*. Notas sobre as problemáticas da atuação profissional dos antropólogos na contemporaneidade ${ }^{* *}$ \\ Duplicating Anthropology. Notes on problems related to the professional action of anthropologists in contemporary times}

Bárbara F. Bustos Barrera***

Resumo: Este artigo discute um tópico fundamental na antropologia, a questão do trabalho profissional do antropólogo. Desconstruindo a ideia de que o profissional estaria associado ao campo da antropologia aplicada, questiona-se a clássica formulação que trata de posições antagônicas nesse caso: de um lado, o trabalho teórico do antropólogo e, de outro, o papel aplicado desse ofício. Nesse contexto, pergunta-se: a antropologia é sempre um trabalho profissional? Há somente um trabalho antropológico? Com base na experiência junto a comunidades mapuche, no sul do Chile, e a instituições públicas de saúde nesse país, procura-se desnaturalizar a referida polaridade que tem acompanhado a história da disciplina, sugerindo a relação entre a dupla atuação do antropólogo, i.e., a interdependência intencionada e necessária entre antropologia implicada e antropologia fundamental, compreendendo a antropologia para além dessa dicotomia.

Palavras-chave: Fazer antropológico; Povos indígenas; Contemporaneidade.

Abstract: This article discusses an important topic in anthropology: the question of the professional work of the anthropologist. Deconstructing the idea that professional work would be associated to applied anthropology, the classical formulation is questioned which deals with antagonistic positions, in this case: on the one hand, the theoretical work of the anthropologist, and on the other, the role applied to this work. In this context the questions that come up are: Is anthropology always a professional job? Is there only one type of anthropological work? Based on the experience of the author with the mapuche communities of southern Chile, and in public health
* A inspiração deste título vem de um artigo de autoria da antropóloga Teresa Durán

Perez, intitulado Duplicando la Antropología desde la Araucanía, Chile (Revista Anthropos, 2005, p. 23-42).

** Trabalho apresentado e aprovado pela Banca do exame de qualificação 2010/2 do Programa de Pós-Graduação em Antropologia Social (PPGAS) da Universidade Federal de Santa Catarina (UFSC). Agradeço os comentários incluídos no parecer da comissão integrada pelas professoras Ilka Boaventura Leite (presidente), Antonella Tassinari e Esther Jean Langdon.

*** Doutoranda do Programa de Pós-Graduação em Antropologia Social da Universidade Federal de Santa Catarina. E-mail: paquirri28@hotmail.com

$$
\text { Tellus, ano 11, n. 20, p. 173-188, jan./jun. } 2011
$$

Campo Grande, MS 
institutions in the same country, the paper seeks to denaturalize this polarity that has accompanied the history of the discipline, suggesting a relationship between a dual role of the anthropologist, that is, an intentional and necessary interdependence between implicated anthropology and fundamental anthropology, understanding anthropology beyond this dichotomy.

Key words: Anthropological action; Indigenous peoples; Contemporaneity.

Era o ano de 1992, e o curso de Antropologia na Universidade Católica de Temuco (UCT) voltava a funcionar depois de vários anos de inatividade sob a ditadura militar no Chile. Esse curso tinha sido reaberto na mesma universidade, na referida cidade do sul do país, e, o que é mais importante, com aqueles alunos, agora professores/as, que tinham sido impedidos de concluir sua formação acadêmica, e cujos destinos haviam se dispersado até esses/as profissionais se reencontrarem no projeto da escola de antropologia. Nesse ano, nessa universidade e com esses professores, eu iniciei a minha formação em Antropologia. À época - fim da ditadura ${ }^{1}$ de Augusto Pinochet e início de uma fase de transição à democracia -, a graduação voltava-se, fundamentalmente, para o estudo da população mapuche e para o desenvolvimento de trabalhos ligados à universidade, à docência e/ou à pesquisa. Embora esses tenham sido os campos que nos foram apresentados, o projeto da escola de antropologia da Universidade Católica de Temuco, dentre suas especializações, contava com a área de Antropologia Aplicada.

Os mapuche constituem a terceira sociedade indígena mais numerosa da América do Sul (depois dos quéchuas e aimaras), e o povo majoritário no Chile, com um total de 602.677 habitantes, segundo o último censo de 2002 , cifra que corresponde a $4 \%$ da população total do país equivalente a 15.750.096 habitantes. Distribuídos preferentemente no sul do Chile - nos setores rurais das regiões de Bío-Bío, La Araucanía, Los Ríos e Los Lagos -, hoje, devido a um longo processo de migração forçada, sua presença é forte também nos bairros da periferia da cidade de Santiago, capital do país. Conheço melhor os mapuche da província de Malleco, na região da Araucanía. Eles moram em comunidades que compreendem entre cinquenta e duzentas pessoas, dedicando-se usualmente à agricultura doméstica e aos cuidados de gado para a subsistência. Tais atividades se complementam, nos últimos dez anos, com trabalhos remunerados em empresas florestais, bem como com a inserção dos indígenas em órgãos de governo, onde exercem atividades como mediadores interculturais. Os mapuche mantêm intensos e complicados vínculos com a sociedade chilena, assim como relações de

\footnotetext{
${ }^{1}$ A ditadura de Augusto Pinochet teve início com o golpe militar de 11 de setembro de 1973, e terminou com o plebiscito de 1989, reunindo ampla maioria que negou nas urnas a continuidade do regime ditatorial.
} 
parentesco, econômicas, políticas e rituais entre as mais de duas mil comunidades situadas no sul do país.

Neste artigo ${ }^{2}$, eu procuro discutir a relação Antropologia e Trabalho Profissional partindo de um dos grandes divisores presentes à antropologia que têm transcendido épocas, paradigmas, métodos e teorias, para se constituir num modo de pensamento e de construção de conhecimento antropológico. O propósito subjacente a tal enfoque é "lembrar aos antropólogos que alguns procedimentos recorrentes em nossa disciplina estão longe de ser óbvios e desprovidos de problemas" (Goldman; Lima, 1999, p. 83). Isso remete a uma discussão disciplinar clássica e ainda muito em voga na antropologia, tematizada igualmente por autores mais ou menos clássicos, debate que tem acompanhado a história da disciplina e que - pode-se afirmar - remonta às origens da antropologia. Refiro-me ao modo de pensamento e ação que coloca em arenas diferentes o trabalho do antropólogo cientista (situado na academia) e o trabalho do antropólogo enquanto aplicado - encontrado preferentemente em órgãos de governo. Depreende-se daqui uma série de desdobramentos cujas questões são rotuladas, na maioria das vezes, de forma dicotômica, tema que tem sido preocupação de vários antropólogos. Nessa perspectiva, de acordo com Evans-Pritchard (1972), trabalho científico versus trabalho prático; antropologia aplicada em oposição a uma antropologia fundamental nos termos de Bruce Albert (1995); trabalho profissional versus trabalho acadêmico segundo Durán e Berho (2003); ou, para mencionar mais uma dentre várias referências possíveis, etnologia clássica versus etnologia do contato tal como foi definida por Eduardo Viveiros de Castro (1999). Assim, o que seria o trabalho profissional na antropologia? O que o definiria? Onde ele estaria situado no contexto dos grandes divisores?

Permito-me fazer aqui alguns apontamentos seguindo a minha experiência, ao longo de dez anos, junto a instituições públicas de saúde no Chile, e de contatos esporádicos com instituições de ensino superior nas quais figurava o curso de antropologia em suas áreas de graduação. Com efeito, a atividade profissional do antropólogo, assim como definida pelos próprios antropólogos, tem sido associada, em termos gerais, à antropologia aplicada; por sua vez, a antropologia aplicada costuma ser atrelada, explícita ou implicitamente, a um trabalho de segunda categoria ${ }^{3}$. Nesse sentido, ele aparece como o "primo

\footnotetext{
${ }^{2}$ Sou grata à minha amiga e colega Marta Magda Antunes Machado pela troca de ideias e pela sua contribuição na revisão do português.

${ }^{3}$ Em algum momento, enquanto decidia e refletia sobre as ideias deste artigo, pensei que a presente discussão poderia se mostrar localista e/ ou retrógada. Acredito que tal questionamento tenha se dado pela forma, às vezes, dissimulada com que o debate aparece aos antropólogos, por exemplo, remetendo-o ao campo restrito da etnologia, como no caso das controvérsias entre João Pacheco de Oliveira e Eduardo Viveiros de Castro. Contudo parece-me interessante retomar as discussões no sentido de mostrar seus diferentes matizes, assim como tornar evidente aquilo que se faz, consciente ou inconscientemente, de modo velado.
}

Tellus, ano 11, n. 20, jan./jun. 2011 
pobre" da antropologia. Tingida por diferentes matizes, mas remetendo a tal discussão, aparece a reflexão de João Pacheco de Oliveira num artigo intitulado Pluralizando tradições etnográficas: sobre um certo mal-estar na antropologia (2004). O mal-estar a que se refere o autor diz respeito "ao desconforto gerado pela suspeita de que a dimensão política assumida pelo trabalho dos antropólogos estaria afetando negativamente o seu rendimento como pesquisadores, afastando-os de forma inevitável de um foco mais científico e acadêmico" (Oliveira, 2004, p. 10-11). Nesse caso, o desconforto seria assim formulado:

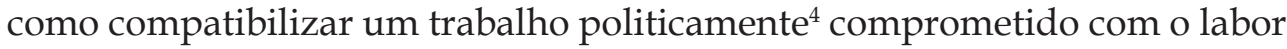
científico exercido de forma neutra?

Trata-se de assunto que sistematizei também num trabalho desenvolvido durante o mestrado, intitulado "O trabalho do antropólogo no campo da saúde dos povos indígenas" (2004). No estudo, a preocupação que me motivava era "refletir sobre o trabalho do antropólogo em contextos extra-acadêmicos ou fora da academia" ${ }^{5}$. Inspirada pelo livro Saúde dos povos indígenas. Reflexões sobre antropologia participativa (Langdon, 2004), eu me questionava então sobre o papel do antropólogo diante de tarefas práticas, como a implantação e o funcionamento de programas especiais dirigidos às populações indígenas, tema que havia sido abordado no meu campo de atuação. Desse modo, atuar em programas de saúde pública é também trabalho do antropólogo, ou o lugar deste está restrito ao âmbito acadêmico? Certamente, naquele momento, tratar o fazer antropológico em pares opostos como algo que eu pensava muito mais em termos de um continuum necessário me parecia questionável. Agora, o meu propósito é sair das pressuposições e tornar evidente o que elas carregam consigo. Ou seja, é interessante pôr em questão a relação automática segundo a qual o trabalho profissional é pensado como antropologia aplicada. Gostaria de refletir sobre como o contexto social global da antropologia, hoje, demanda a suspensão dessa homologação, clamando pela ampliação do que se entende por trabalho profissional antropológico. Como bem afirma Marc Augé (2006, p. 9, tradução da autora): “[...] interrogar hoje em dia pelo ofício do antropólogo significa se interrogar acerca do mundo atual". Em última instância, isso implica, de acordo com o próprio autor, "um desafio intelectual que lança à antropologia evidência cada dia mais pronunciada de formas inéditas de contemporaneidade" (Augé, 1994, p. 61, tradução da autora).

\footnotetext{
${ }^{4}$ Neste trabalho, não é meu interesse aprofundar o assunto do "engajamento político" na/ da antropologia, estritamente pensado nesses termos. Considerando o interesse da questão política, meu argumento privilegia a ideia de não ser esta uma "posição" (ou algo do gênero) exclusiva de algum tipo de antropologia, o que procuro apontar neste texto.

${ }^{5}$ Utilizo aqui essas categorias - extra-acadêmicos e fora da academia - tão somente para situar um ponto desde o qual procedo a uma crítica que toma maior proporção neste ensaio como um todo.
} 
Portanto busco destacar e desenvolver aqui a ideia de que a antropologia não pode ser pensada senão como uma pluralidade de fazeres e formas de expressão do trabalho profissional. Antropologias no plural, no sentido de Menezes Bastos (2010, p. 3), "como uma primeira grande marca da antropologia, uma pluralidade que tem sido - e é - tensa (como são tensas as relações entre os paradigmas no interior da matriz disciplinar antropológica)". Nessa perspectiva, a definição do que será o trabalho profissional do antropólogo dependerá da própria disciplina em seus objetivos e referenciais teóricos, metodológicos e políticos. Assim, a própria ideia de antropologia como atividade profissional deve ser repensada (Rifiotis ${ }^{6}$, comunicação pessoal). Cabe, pois, perguntar-se: a antropologia é sempre uma prática profissional? Há um só trabalho antropológico? Neste artigo, as evidências do trabalho antropológico indicam que o que fazemos dentro e fora da academia, por exemplo, é, em todo caso, trabalho profissional antropológico. No caso, há uma multiplicidade de "fazeres", o trabalho profissional antropológico é amplo (idem). Agora, ao me voltar para as inquietações acima apontadas - no citado trabalho final da disciplina Antropologia da Saúde no curso de mestrado -, eu não poderia deixar de questioná-las neste momento e fazer delas o início de outra discussão. O que seria uma antropologia "extra-acadêmica"? É extra porque é feita fora da academia? Ora, para fazer antropologia, é preciso passar por um curso de formação nessa área, aprender sobre teorias e métodos, passar pelo ritual do trabalho de campo etc. Nesse sentido, uma vez que nos tornamos antropólogos, somos regidos por um mesmo código de ética, participamos dos mesmos congressos, publicamos nas mesmas revistas. Então, em que consiste o colocar-se fora da academia? Ou ainda, de que maneira pode ser pensado, por exemplo, o trabalho desenvolvido por Terrence Turner entre os Kaiapó? ? Qual o estilo de antropologia que ele representa?

Parece-me que o cenário atual da antropologia exige outras (e diversas) formas de atuação profissional. Penso, seguindo a abordagem de Durán e Berho, que um papel transversal, alternado e dual do trabalho profissional do antropólogo estaria em maior e melhor sintonia com as exigências da contemporaneidade, dos sujeitos aí atuantes, aliás, esse é o modo que compreendo como o do antropólogo atuando e atuante. Em outras palavras:

Isto quer dizer que acreditamos ser possível o fazer científico no âmbito da antropologia aplicada enquanto ela se assume como um prolongamento da antropologia geral, mas no marco de um enfoque desde o qual o especialista se dispõe a procurar explicações com o intuito de

\footnotetext{
${ }^{6}$ Sou grata ao professor Theophilos Rifiotis por ter me despertado para algumas das ideias contidas neste artigo, bem como ter se disponibilizado a discuti-las.

${ }^{7}$ Agradeço igualmente ao professor Rafael José de Menezes Bastos pela sugestão da leitura do artigo "Imagens desafiantes. A apropriação Kaiapó do vídeo" (1993), e por sua disposição em colaborar com o debate deste ensaio.
} 
compreender "nossas circunstâncias" e "melhor atuar" no âmbito em que a ação social se expressa em contextos dados. (Durán e Berho, 2003, p. 36, tradução da autora).

Como lembra Marc Augé, a antropologia tem que "discernir, mediante modelos críticos elaborados pela própria disciplina, o movimento que a impulsiona pouco a pouco, apesar de si mesma, talvez, a enfrentar o mundo do qual ela faz parte e a renunciar as miragens do exílio, da fuga e dos exotismos" (Augé, 1994, p. 61, tradução da autora).

\section{Antropólogos (perdidos?) na contemporaneidade}

Como foi mencionado acima, é impossível desconhecer as transformações das últimas três décadas no campo social, cultural, econômico e político do contexto mundial. E esta é uma questão interessante em termos dos objetos da antropologia, pois as ciências sociais (dentre as quais está a antropologia) "[...] afrontam diretamente o problema da mudança histórica, da mudança de contexto: isso forma parte de seu objeto" (Augé, 2006, p. 15, tradução da autora). Por conseguinte, a atividade do antropólogo é submetida também a essas mudanças, as quais exigem uma reeducação e um aguçamento dos sentidos, advertindo para novos contextos e sua tematização como de interesse antropológico. Sensível a essa questão, George Marcus, em Etnography through thick $\mathcal{E}$ thin, afirma que a antropologia atravessa um momento de transição crítica nos planos teórico, metodológico e temático. Isso implica levar em conta "o mundo em que hoje os etnógrafos trabalham, aceitando problemas que na realidade foram reconhecidos no passado, mas que foram ignorados ou omitidos pela prevalência de outras ideias dominantes" (Marcus, 1998 [1986], p. 77).

Há nesse autor - como em outros que pesquisaram, pensaram e escreveram à sua época - o que Marshall Sahlins (1997) observa em O 'Pessimismo Sentimental' e a experiência etnográfica: por que a cultura não é um 'objeto' em via de extinção (parte II). Por um lado, haveria na antropologia uma mistura de medo e incapacidade de compreender "as novas estruturas culturais da modernidade", e, por outro, Sahlins defende a ideia de que a cultura não é um "objeto" em vias de extinção. Ora, o que está por trás dessas afirmações não é mais do que dúvida em torno da continuidade (ou não) da antropologia num mundo globalizado, a qual se pergunta sobre a vigência e validade de seu objeto - "a cultura" -, que, pressionado pelos vaivens da modernidade, se metamorfosearia a tal ponto, não sendo possível seu reconhecimento pensado em termos tradicionais. Desse modo, Marshall Sahlins torna explícito um conjunto de fenômenos que vêm sendo estudados e, ao mesmo tempo, ignorados pela antropologia dos últimos 30 anos. Esses fenômenos dizem respeito ao 
surgimento da "consciência cultural" dos povos e ao "uso autorreflexivo da cultura" em contextos políticos e econômicos globalizados, assim como às "novas formas de produção histórica".

Efetivamente, procuro retomar aqui algo da minha experiência de campo à época da graduação (1997), quando me deparei com situações que se aproximavam da reflexão crítica da antropologia pontuada por Marcus, e de certo pessimismo apontado por Sahlins. Nessa perspectiva, minha pesquisa abordava o processo de adaptação de uma comunidade mapuche que havia se dividido, parte dela deixando suas terras de origem para instalar-se num território distante adquirido pelo Estado chileno ${ }^{8}$. Esse deslocamento aconteceu, porque a referida comunidade, como muitas outras, enfrentava problemas de escassez de terra. Tal situação, por sua vez, se produzia devido ao fenômeno social de aumento do número de famílias no espaço da comunidade, somando-se o fato de que os mapuche foram obrigados a se estabelecer em reducciones, i.e., parcelas fixas, estritamente delimitadas e em caráter definitivo ${ }^{9}$, como resultado do processo equivocadamente chamado de "Pacificación de la Araucanía" no final do século XIX.

\footnotetext{
${ }^{8}$ No ano de 1993, com o primeiro governo democrático após a ditadura, promulga-se a Lei Indígena 19.253, que cria a Corporação Nacional de Desenvolvimento Indígena (CONADI), ligada ao Ministério de Planificação e Cooperação. Ela cria também o Fundo de Terras e Águas Indígenas (FTAI), por intermédio do qual as comunidades indígenas podem ou demandar a falta de terras ou reivindicar a usurpação delas por meio formal num longo e complexo processo, cabendo ao Estado a compra de terras. É oportuno destacar que a diferenciação entre demanda e reivindicação aqui não é menor em importância. As comunidades que conseguem provar, mediante documentação, que as terras reivindicadas foram usurpadas, i.e., que pertenceram a seu território ancestral original podem exigir sua devolução, cabendo ao Estado a negociação com os que as ocupam no momento da reivindicação, bem como a compra e restituição à comunidade. O comum nesses casos é que as terras reivindicadas sejam vizinhas das terras ocupadas pela comunidade no momento da compra, o que resulta numa expansão do espaço, e, o que é mais importante, os membros da comunidade permanecem no mesmo espaço territorial ampliado. Pelo contrário, numa demanda por terras quando a comunidade não tem como comprovar usurpação ou quando esta não ocorreu, nesse caso, resta à comunidade optar por terras em qualquer lugar em que elas existam. Assim, há uma alta probabilidade de que a comunidade tenha que se deslocar até lugares distintos e distantes, para conseguir o propósito da ampliação das terras. Isso pode implicar ou o abandono por parte da comunidade das terras originais ou a sua divisão, como aconteceu com a comunidade Ailío no tempo em que eu realizava o trabalho de campo na graduação.

${ }^{9}$ Cabe lembrar, aqui, que os mapuche possuem um padrão de residência patrilocal: "As mulheres vão morar na casa dos pais do marido, quer dizer, abandonam seu grupo para ir morar no grupo do marido, e, por outro lado, há também as mulheres que chegam provenientes de outros grupos pelo mesmo motivo. Pode acontecer que homens venham morar também na comunidade (da mulher) por casamento, mas este é um fenômeno menos habitual, predominando o padrão de residência patrilocal" (Bustos, 2006, p. 17). Em outros termos, ao se constituir nova família por casamento, o pai - em geral, o dono da terra - tem que dividir seu já escasso terreno entre seus filhos (homens) casados; estes irão proceder de igual modo com seus filhos homens, e assim sucessivamente.
}

Tellus, ano 11, n. 20, jan./jun. 2011 
No caso da comunidade com que trabalhei durante meu trabalho de conclusão de curso (Nicolas Ailío II), sua solicitação de reivindicação e recuperação territorial não foi aceita, menos por falta de provas confirmando que o território reclamado (vizinho do território ocupado por ela naquele momento) lhes pertencia ancestralmente, e mais por ser o dono à época um personagem muito poderoso da região, cuja influência acabou impedindo a reivindicação da citada comunidade. Assim, para cumprir com o propósito de ampliar as terras, a metade da comunidade Nicolas Ailío teve que sair do seu local de origem para um terreno num município distante cerca de $200 \mathrm{~km}$. Segundo os técnicos da Corporação Nacional de Desenvolvimento Indígena (CONADI), o terreno cumpria com todos os requisitos de terra de alta produtividade. E nesse complicado processo, a outra metade da comunidade Ailío decidiu ficar nas terras ancestrais.

Lembro-me que, no momento do trabalho de campo, eu me questionava sobre o porquê desta decisão da comunidade: sair do seu lugar de origem, onde ela tinha passado toda a vida, para ir morar num lugar distante, diferente, onde as redes de relações com outras comunidades mapuche se fariam limitadas, longe de sua parentela, sendo que as novas terras se situavam num município ocupado por fazendeiros-colonos alemães. Interrogava-me sobre o que seria, então, essa "cultura mapuche", como ela estaria se expressando na decisão de divisão da comunidade? Não fazia parte de sua cultura o prevalecimento dos laços de parentesco? Não dizia respeito à sua "tradição" a relação com a terra? No entanto, essas questões não foram explicitadas no meu trabalho de conclusão de curso, talvez por eu não saber formulá-las. $\mathrm{Ou}$ ainda por pensar à maneira de Augé:

[...] os etnólogos têm acreditado frequentemente que estavam estudando um mundo em vias de desaparição, enquanto que, como antropólogos, assistiam ao nascimento, certamente doloroso e complicado, de um novo mundo, para cujo conhecimento eles têm hoje a capacidade e o dever de contribuir. (Augé, 2006, p. 45).

Independentemente de minhas dificuldades de pesquisadora, as transformações ocorriam, antecipando-se ao instrumental e à minha própria sensibilidade antropológica naquele especial momento. Era também, em certa medida, a invasão do "pessimismo sentimental" formulado por Sahlins: a cultura em vias de extinção?

Numa fase menos "pessimista" da contemporaneidade, por assim dizer, encontram-se as reflexões de Boaventura Leite (2005) constatando um novo cenário na prática antropológica: os laudos periciais. Isso exige, pois, que se repense o trabalho profissional do antropólogo. Nessa perspectiva, a autora analisa como a confluência da chegada de governos democráticos aos países da América Latina e da emergência de crescente visibilidade da consciência reinvidicativa dos povos indígenas ou outros grupos étnicos possibilitou 
a consolidação da perícia antropológica. Desse modo, compreendo que o surgimento de novos cenários de atuação profissional do antropólogo, hoje, depende muito mais de problemáticas oriundas da sociedade e, ao mesmo tempo, pensadas pelos antropólogos, que de certa "autolocalização" destes num ou noutro "lugar" das dicotomias - referentes aos grandes divisores apontadas no início do presente artigo. Por outro lado, Boaventura Leite mostra como o trabalho da perícia antropológica situa-se num campo mais amplo da disciplina que o de simples exercício técnico. E ainda outras preocupações são levadas em conta quando “[...] fica evidente que o trabalho do antropólogo perito não se constitui num mero parecer técnico, mas reflete uma preocupação central: o aprofundamento resultante da pesquisa de campo etnográfica, elaborada na vivência 'in loco' e que busca realçar o ponto de vista dos grupos pesquisados" (Boaventura Leite, 2005, p. 17). Ou seja, a perícia antropológica - assim como outras atividades vinculadas a preocupações sociais e/ou que respondem a solicitações provindas de grupos específicos ou de instâncias institucionais - requer a realização de trabalho de campo e uma reflexão antropológica abrangente para compreensão de problemáticas diversas. Tem-se aqui uma ampliação do trabalho profissional não ligado unicamente à práxis, mas também exigindo o uso de seus aspectos disciplinares.

Em sintonia com as ponderações de Boaventura Leite, encontra-se o estudo de Jean Langdon propondo uma avaliação crítica do sistema de "atenção diferenciada" no campo da saúde indígena. Duas questões são pontuadas pela autora, e ajudam a reforçar meu argumento acerca de contextos, cenários, desafios colocados pela contemporaneidade à antropologia. Por um lado, "[...] aumento das associações indígenas e suas demandas de pesquisadores antropólogos e de apoio político e estratégico" (Langdon, 2004, p. 33). Por outro lado, o fato de ter a legislação brasileira ampliado, mediante a criação de novos órgãos governamentais, maior demanda pela atuação antropológica nos assuntos que têm a ver com a saúde das populações indígenas. Com efeito, os dados remetem ao que vem acontecendo no Chile, nesse campo, nos últimos anos. Cada vez mais antropólogos são requisitados, seja para formar as equipes permanentes de instituições governamentais, seja para prestar assessorias em temas específicos. Quando eu trabalhava no Ministério da Saúde do Chile (2007-2009), no Programa de Saúde dos Povos Indígenas, havia cerca de 15 antropólogos atuando nesse programa, o que correspondia a mais da metade do total da equipe no país. Como entender a crescente demanda por antropólogos em espaços não tradicionais? O que é aí esperado do antropólogo? Em que medida espaços ditos "não tradicionais" se tornam "tradicionais" de atuação profissional do antropólogo no mundo contemporâneo? 


\section{Discutindo o papel dual da antropologia}

As problemáticas que caracterizam o cenário social global atualmente suscitam, para a atuação do antropólogo, outras e novas questões a serem pensadas. Ao antropólogo é exigido que duplique sua atuação. Tal duplicidade o coloca frente a "uma espécie de dilema relacionado com a multiplicidade de solicitações a que respondemos [os antropólogos] de modo cada vez mais constante e direto" (Rifiotis, 1998, p. 41). O que faz o antropólogo nessa hora? Nega-se? E para onde vão tais solicitações? Como mostra Coelho dos Santos, "[...] a antropologia brasileira mudou muito, diversificando seus campos de interesse. Não são poucos, portanto, os casos de antropólogos que vivenciam dilemas éticos" (Coelho dos Santos, 1998, p. 86). Os dilemas, é bom salientar, não são necessária e unicamente aqueles pelos quais o antropólogo se depara com questões de risco para a vida das pessoas ou dos grupos por ele investigados. Trata-se, antes, de dilemas éticos que emergem da prática cotidiana de sua atuação e que resultam de mudanças vindas de todos os lados, por sua vez, avançando em distintas direções. A título de exemplo, pode-se indagar: o laudo antropológico para demarcação de terras, a capacitação sobre antropologia para diversas áreas profissionais da sociedade civil, o apoio a associações indígenas para formulação de projetos sobre vídeo nas aldeias, dentre outros, não seriam produtos de novos cenários para a antropologia? Uma vez mais é possível perguntar: qual a posição do antropólogo requisitado para se incorporar a um órgão de governo e trabalhar no campo da saúde indígena? Essa questão que parece óbvia coloca, no entanto, aquilo que Coelho dos Santos chama dilema ético.

Hoje, como enfatiza Rifiotis, e como venho observando neste texto, o dilema ético nasce de uma dupla exigência "que não pode ser minimizada em suas implicações éticas e científicas. Compatibilizar o discurso analítico e o de intervenção, polos limítrofes, é uma dificuldade que compartilho com outros colegas, sobretudo frente à crescente demanda de diálogo e cooperação com grupos sociais, movimentos sociais, bem como órgãos de governo, particularmente com as políticas civis e militares" (Rifiotis, 1998, p. 41). Eis a dificuldade das demandas, que os antropólogos não podem desconhecer ou ignorar, sob pena de negarem, de algum modo, sua própria práxis fundadora de "ouvir" o outro. Penso aqui na má fama do trabalho profissional ligado à antropologia aplicada nos termos tratados no início deste artigo. Parece-me que, nos dias de hoje, essa má fama merece ser questionada: "A antropologia elegeu novos objetos de estudo, novos campos de atuação profissional" (Laraia, 1998, p. 91), e, agora, ela estaria na condição de corresponder a essa eleição responsabilizando-se nesse sentido ${ }^{10}$.

\footnotetext{
${ }^{10}$ Numa situação em que o/a antropólogo/a é solicitado/a, creio que seria possível a ele/a optar por uma resposta positiva ou negativa. No entanto, em ambos os casos, o/a profissional deveria pensar nas implicações de seu posicionamento.
} 
Agora, os contextos da contemporaneidade demandam uma dupla atuação profissional do antropólogo. É o que observo, por exemplo, no Programa de Pós-Graduação em Antropologia Social da Universidade Federal de Santa Catarina (PPGAS/UFSC). Antropólogos/as inseridos num ambiente acadêmico-universitário participam também ativamente de maneira crítica (atenta e vigilante) de problemáticas sociais definidas pelos grupos com os quais trabalham. "Trata-se de tornar clara a problemática da intervenção como prática antropológica no contexto atual" (Langdon, 2004, p. 35). Isso significa tomar as demandas e a participação de antropólogos - nas variadas áreas, universidades, associações indígenas, órgãos de pesquisa, órgãos de governos, ONGs etc. - como campo de conhecimento antropológico. Parece-me que não se trata de estar a favor ou contra a participação da antropologia em diversos contextos. O ponto em questão é o que fazer nesses contextos. Trata-se de perguntar uma vez mais, no afã revisionista da antropologia lembrado por Augé, qual o papel do antropólogo aqui e/ou em qualquer lugar? Do meu ponto de vista, o problema não estaria no fato do antropólogo se dispor a participar e responder às solicitações da sociedade pelas distintas vozes (órgãos de governo, ONGs, associações indígenas, grupos quilombolas, universidades, dentre outras instâncias). O problema, antes, seria como o antropólogo respondeu, responde e pode continuar respondendo frente às exigências do mundo contemporâneo.

Embora a antropologia tenha expandido seus lugares, problemas e objetos, isso não significa que seu alcance seja infinito; pelo contrário, os novos lugares, problemas e sujeitos criaram (e criam), ao mesmo tempo, limites para a atuação profissional. Este é o questionamento que levanta Miriam Hartung a propósito do peso do argumento antropológico no jogo de poderes que se tece em contextos que são essencialmente políticos. A autora se interroga sobre as possibilidades reais de intervenção do profissional: "[...] até que ponto o argumento antropológico pode intervir em casos [por exemplo, os de reconhecimento de terra] cuja arena é política" (Hartung, 2005, p. 145). Situação semelhante ocorreu quando do meu trabalho no Ministério da Saúde no Chile, em que o argumento antropológico era usualmente contestado pelo saber biomédico, burocrático e administrativo. Ou seja, o argumento antropológico - como se depreende de estudos sobre rituais - não tem eficácia ${ }^{11}$ por si só. É preciso da orquestração coordenada de atores, objetos e poderes para que ele (o argumento) aconteça e logre o propósito desejado, e para que a eficácia seja percebida como tal pelos participantes. Comparativamente, o argumento

\footnotetext{
${ }^{11}$ Tomo emprestada a palavra eficácia do artigo da professora Miriam Hartung, intitulado "Os limites da assessoria antropológica: o caso dos descendentes de escravos e libertos da Invernada Paiol de Telha - PR" (2005). Porém uso-a nos termos de Lévi-Strauss no célebre artigo "A eficácia simbólica" (1969).
}

Tellus, ano 11, n. 20, jan./jun. 2011 
antropológico pode atuar de maneira similar. Talvez a eficácia da argumentação esteja na habilidade do antropólogo de relevar, destacar, reunir e pôr em diálogo as diferentes vozes. Porém, como assevera Hartung, em algumas ocasiões - dizer muitas não estaria longe da realidade -, as intervenções do antropólogo, de fato, têm limites.

Quando comecei alguma prática profissional em saúde no ano de 2001, no sul do Chile, ao lado de profissionais dessa área e junto a comunidades mapuche, ocorreram desencontros na relação com colegas de trabalho. Eu tentava sugerir uma linha de pesquisa e atividades em área reconhecida como exclusivamente da biomedicina. No Programa de Saúde Mapuche, eu discutia com profissionais da saúde a necessidade de materializar-se uma linha investigativa não limitada aos estudos epidemiológicos clássicos, e, embora eu os reconhecesse como ponto de partida para maior compreensão do fenômeno, sugeria abrir-se a áreas que, desde uma concepção biomédica, não eram vistas como parte do campo da saúde. Assim, em parceria com a escola de antropologia onde me formei, realizou-se uma pesquisa que tinha o propósito de revelar o homólogo sociocultural do conceito de saneamento ambiental. Intuíamos que tal conceito não captava a concepção dos próprios mapuche sobre seu meio. Ou seja, o estudo tentava aproximar-se do conhecimento mapuche quanto à temática da contaminação ambiental.

A pesquisa constatou que a população indígena do setor da cordilheira possuía uma forma própria de definir e agir com respeito ao saneamento ambiental e a seus distintos componentes. Especificamente, o estudo permitiu aproximar-se do "conceito local" de lixo, baseado numa concepção de "organização do meio". De modo semelhante, aconteceu com respeito à definição mapuche de contaminação. Esta tinha a ver com um sentido de consciência das mudanças socioculturais e ambientais ocorridas ao longo de 50 anos, e com a idéia de intervenção (negativa) no espaço natural próprio. Ora, o conceito local de contaminação apontou, de fato, para a ausência de elementos da natureza que ancestralmente estiveram presentes e que, em consequência de mudanças socioculturais e ambientais, naquele momento eram inexistentes. Isso significa que a referida população não reconhecia a presença desses elementos em seu meio. Embora a pesquisa tenha evidenciado uma realidade desconhecida tanto pela antropologia quanto pelos profissionais da saúde, os resultados do estudo não foram acolhidos e receberam fortes questionamentos por parte das equipes de saúde. Nesse caso, penso que a reação correspondia ao estereótipo de que as práticas das populações indígenas "eram erradas". Pontualmente, aí estava em jogo a ideia da população mapuche não ter "normas de higiene" e de serem as próprias comunidades indígenas as responsáveis pela contaminação e pela deterioração do seu meio.

Lembro-me de uma discussão acirrada e de enorme frustração por eu não ter conseguido colocar em comum algumas ideias sobre como as comuni- 
dades mapuche - com as quais trabalhávamos - pensavam e agiam quanto ao saneamento ambiental. Fui afetada ${ }^{12}$. Como antropóloga, meu argumento se viu limitado. Faltaria ainda muito tempo para que a antropologia começasse a fazer sentido para algumas das pessoas que ali trabalhavam. Mais tarde, a chegada de profissionais mapuche para integrar essa equipe, juntamente com a compreensão do conhecimento antropológico partilhado para além da disciplina, e o fato de as organizações mapuche começarem a falar de meio ambiente etc. tiveram influência direta em certa recepção da perspectiva antropológica por parte de alguns.

\section{Duplicando em palavras finais}

Se alguma ideia pode ser apreendida das reflexões aqui formuladas, é esta de que os paradigmas definidores do fazer antropológico em oposições - colocando teoria de um lado e prática de outro - constituem temas e discussões que acompanham o desenvolvimento da própria antropologia e seu crescimento. Seria interessante recorrer à perspectiva histórica para indagar desde quando estas duas - teoria e prática - estiveram separadas, ou desde quando estiveram juntas, ou ambas as coisas. A resposta a tal indagação poderia ser a origem das controvérsias. Ao mesmo tempo, eu penso que esse debate tem perdido força, uma vez que, a despeito de ser atual e presente à antropologia, o assunto aponta para outras tendências, conectando muito mais que opondo as antropologias.

Num texto de mais de uma década, Bruce Albert ${ }^{13}$ (1995) discute a relação (ou não) entre antropologia aplicada e antropologia fundamental. $O$ interessante no argumento do autor é que, de um lado, ele recusa a oposição "tanto convencional como inconsistente entre antropologia fundamental e pesquisa aplicada", e, de outro, ele postula "uma interdependência possível, na antropologia das minorias, entre pesquisa científica e implicação social" (Albert, 2009, p. 87). Albert é a favor de dissolver a mencionada oposição para apostar na ideia de uma "antropologia implicada", caracterizada pelo compromisso ético, social e político. Em outras palavras:

[...] uma pesquisa fundamental, intelectual e socialmente investida na situação histórica das sociedades que ela [a antropologia] estuda, e

\footnotetext{
${ }^{12}$ Afetada no sentido de Favret-Saada (2005, p. 160) quando afirma que: "Aceitar ser afetado supõe, todavia, que se assuma o risco de ver seu projeto de conhecimento se desfazer. Pois, se o projeto for onipresente, não acontece nada. Mas, se acontece alguma coisa e se o projeto de conhecimento não se perde em meio de uma aventura, então uma etnografia é possível". ${ }^{13}$ Apesar de eu discordar de várias questões do artigo de Bruce Albert, parece-me importante trazê-lo à luz, pois creio que ele serve como um barômetro para a discussão. Por outro lado, os reparos desse artigo apontariam em especial para a crítica a uma espécie de etnocentrismo velado em torno de como ele pensa e entende a antropologia na França.
}

Tellus, ano 11, n. 20, jan./jun. 2011 
suscetível de mobilizar suas competências em favor de sua conquista de autodeterminação. (Albert, 1995, p. 118).

No sul do Chile, a antropóloga Teresa Durán ${ }^{14}$ tem trabalhado, na última década, as possibilidades de articulação entre o que ela denomina "o papel profissional e o papel disciplinar do antropólogo". Essa reflexão, nascida de sua própria práxis, deu origem a Antropologia Aplicada Interativa, concebendo o fazer antropológico como "uma abordagem teórico-metodológica de orientação aplicada que permite desenhar programas de participação antropológica para o conhecimento, entendimento e intervenção em problemáticas sociais" (Durán, 2009, p. 283). Por outro lado, há também debates cujo enfoque tende à polarização e definitivamente funda uma quebra entre o que tem sido denominado de duas etnologias no contexto do Brasil, ou melhor, no âmbito do Museu Nacional do Rio de Janeiro: a etnologia clássica e a etnologia do contato interétnico. Distinção que, desde meu ponto de vista, reforça uma oposição entre aquilo que hoje a sociedade quer ver cada vez mais se articulando. Ora, essa junção não deve ser entendida como uma nuvem de indefinições, ou melhor, não se pode pensar em um mesmo campo de ação; nem que a antropologia aplicada e a antropologia fundamental são apenas um "erro" de brigas passadas. Trabalho profissional e trabalho acadêmico, de fato, são campos diferenciados, mas é preciso, como antropólogos a quem é dado viver a contemporaneidade, fazer uma inter-relação necessária e intencionada.

Ao me chamarem para trabalhar no Programa de Saúde Mapuche, as pessoas que haviam decidido pela contratação viam em minha presença um incômodo para o seu trabalho. A sua imagem dos antropólogos era a de alguém que poderia estabelecer diálogo com as comunidades mapuche, ajudando à entrada de técnicos e profissionais de saúde na dinâmica das comunidades, porém, colocando-se sempre ao lado dos mapuche. Tratava-se de uma visão complexa que me mantinha em semelhante condição. Quando iniciei minha prática antropológica no Programa, o que eu levava comigo eram os cinco anos do curso de antropologia na Universidade Católica de Temuco. Aliás, sem essa formação, possivelmente eu não teria sido chamada para a referida atividade profissional. Agora, uma vez estando ali, fiz-me valer de conhecimentos adquiridos na escola de antropologia e fui construindo a minha própria práxis. Desse modo, teoria e práxis são chamadas a se

\footnotetext{
${ }^{14}$ Enquanto pensava e escrevia este artigo, assim como em inúmeras outras ocasiões, eu contei com a orientação da docente que igualmente conduziu a elaboração do meu TCC. Profissional exemplar, a professora Teresa Durán Perez marcou toda a minha formação como pesquisadora. Antropóloga chilena, ela dedicou sua vida ao ensino de antropologia no sul do Chile e ao trabalho comprometido com o povo mapuche. Infelizmente, em abril de 2011, Teresa veio a falecer. Fica aqui registrada a homenagem a essa intelectual cuja colaboração se mostra fundamental na construção do argumento deste texto. Dedico-o em sua memória.
} 
constituírem conjuntamente. É o que a contemporaneidade, com seus atores, está proclamando: uma amplidão (amplitude) do trabalho profissional do antropólogo.

\section{Referências}

ALBERT, Bruce. Anthropologie appliquée ou «anthropologie impliquée»? Ethnographie, minorités et développement. In: BARÉ, Jean-François (Org.). Les applications de l'anthropologie. Un essai de réflexion collective depuis la France. Paris: Karthala, 2009 [1995].

AUGÉ, Marc. El oficio del antropólogo. Sentido y libertad. Barcelona: Editorial Gedisa, 2006. disa, 1994.

Hacia una antropología de los mundos contemporáneos. Barcelona: Editorial Ge-

BOAVENTURA LEITE, Ilka. Laudos periciais: um novo cenário na prática antropológica. In: BOAVENTURA LEITE, Ilka (Org.). Laudos periciais antropológicos em debate. Florianópolis: ABA/NUER, 2005.

BUSTOS, Bárbara. Novas configurações rituais. O contexto sociopolítico da realização do ngillatun entre os mapuche de Tranaman no sul do Chile. 2006. Dissertação (Mestrado em Antropologia Social) - PPGAS/Universidade Federal de Santa Catarina, Florianópolis, 2006.

COELHO DOS SANTOS, Silvio. Notas sobre ética e ciência. In: BOAVENTURA, Ilka (Org.). Ética e estética na antropologia. Florianópolis: PPGAS/UFSC/CNP, 1998.

DURÁN, Teresa. Teoría antropológica de la acción. Un contrapunto desde la praxis. Revista Intersecciones en antropología, n. 10, p. 279-293, 2009.

. Duplicando la Antropología desde la Araucanía, Chile. Revista Anthropos, n. 207, p. 23-42, 2005.

DURÁN, Teresa; BERHO, Marcelo. Antropología interactiva: conciencia y práctica dual del rol del antropólogo en una sociedad multiétnica y multicultural. Revista CUHSO, n. 7, v. 1, p. 34-48, 2003.

EVANS-PRITCHARD, Edward E. Antropologia Social. São Paulo: Editora Perspectivas do Homem. 1972.

FAVRET-SAADA, Jeanne. Ser afetado. Cadernos de Campo, n. 13, p. 149-153, 2005.

GOLDMAN, Márcio; LIMA, Tânia Stolze. Como se faz um grande divisor. In: GOLDMAN, Márcio. Alguma antropologia. Rio de Janeiro: Relume Dumará, 1999, p. 83-92.

HARTUNG, Miriam. Os limites da assessoria antropológica: o caso dos descendentes de escravos e libertos da Invernada Paiol de Telha-PR. In: BOAVENTURA, Ilka (Org.). Laudos periciais antropológicos em debate. Florianópolis: ABA/NUER, 2005.

LANGDON, Esther Jean. Uma avaliação crítica da atenção diferenciada e a colaboração

Tellus, ano 11, n. 20, jan./jun. 2011 
entre antropologia e profissionais da saúde. In: LANGDON, Esther Jean; GARNELO, Luiza (Orgs.). Saúde dos povos indígenas. Reflexões sobre uma antropologia participativa. Rio de Janeiro: Contracapa/ABA, 2004.

LARAIA, Roque. Ética e antropologia: algumas questões. In: BOAVENTURA, Ilka (Org.). Ética e estética na antropologia. Florianópolis: PPGAS/UFSC/CNPq, 1998.

LÉVI-STRAUSS, Claude. A eficácia simbólica. In: . Antropologia estrutural. Rio de Janeiro: Tempo Brasileiro, 1969. p. 168-185.

MARCUS, George. Power on the extreme periphery: the perspective of Tongan elites in modern world system. In: . Ethnography through, thick \& thin. Princeton: [s.n.], 1998.

MENEZES BASTOS, Rafael José de. Antropologia é aquilo que o antropólogo faz. Antropologia? - antropologias. Manuscrito inédito, 2010.

OLIVEIRA, João Pacheco de. Pluralizando tradições etnográficas: sobre um certo malestar na antropologia. In: LANGDON, Esther Jean, GARNELO, Luiza (Orgs.). Saúde dos povos indígenas. Reflexões sobre uma antropologia participativa. Rio de Janeiro: Contracapa/ABA, 2004.

RIFIOTIS, Theophilos. Direitos humanos: declaração, estratégia, campo de trabalho e ética. Boletim da ABA, Niterói, n. 30, 2o- Semestre, p. 41-42, 1998.

SAHLINS, Marshall. O "pessimismo sentimental" e a experiência etnográfica: por que a cultura não é um objeto em vias de extinção? (Parte II). Mana, Rio de Janeiro, n. 3, v. 2, p. 103-150, 1997.

TURNER, Terrence. Imagens desafiantes: a apropriação Kaiapó do vídeo. Revista de Antropologia, São Paulo, v. 36, p. 81-121, 1993.

VIVEIROS de CASTRO, Eduardo. Etnologia Brasileira. In: MICELI, Sérgio (Org.). O que ler na ciência social brasileira. (1970-1995). São Paulo: ANPOCS, 1999. v. I - Antropologia, p. 109-223.

Recebido em 26 de janeiro de 2011

Aprovado para publicação em 6 de maio de 2011

188 B.F.B. BARRERA. Duplicando a Antropologia. Notas sobre as problemáticas da atuação... 